\title{
A Prototype Model for Generating Electricity Using Solar Parabolic Dish, Stirling Engine and Solar Tracking System
}

\author{
Abubakar Siddique ${ }^{1}$, M. Waqar Hassan², M. Kaleem Aslam³ ${ }^{3}$ M. Nadeem Aslam³ ${ }^{3}$ Yonghai Xu1, \\ Waseem Aslam ${ }^{1}$ \\ ${ }^{1}$ School of Electrical \& Electronics Engineering, North China Electric Power University (NCEPU), Beijing, \\ China. \\ 2 Department of Electrical Engineering, the Islamia University of Bahawalpur, Pakistan. \\ ${ }^{2}$ Department of Electrical Engineering, Institute of Southern Punjab (ISP), Pakistan. \\ * Corresponding author. Tel.: +8613651262732; email: engr.abs@yahoo.com \\ Manuscript submitted June 12, 2018; accepted September 10, 2018. \\ doi: 10.17706/ijcee.2018.10.4.308-317
}

\begin{abstract}
Energy crises refers to any shortfall in the supply of energy resources to an economy. To counter these crises, renewable energy resources provide a significant potential. As most of the renewable energy resources never die, so we can obtain continuous supply from these sources. Among these sources, solar energy provides greater potential for electrical power. To use solar energy, one of the best approach is to design Parabolic Solar Dish which is more efficient than other solar technologies. In order to get maximum power output, needs to keep the dish aligned with the sun. This paper deals with the generation of electricity using parabolic shaped dish. A model is designed which contains a solar parabolic shaped dish, Stirling engine, dynamo and a solar tracker. Solar energy is focused on the cylinder of a Stirling engine which is attached at the focal point of the dish. This Stirling Engine is coupled to a Dynamo through a rubber belt and the dynamo produces output. Moreover a Solar Tracker Circuit is designed which rotates the dish automatically in the direction of sun. This reduces the use of fossil fuels and have greater efficiency.
\end{abstract}

Key words: Parabolic solar dish, power output, aligned, solar tracker circuit, Stirling engine, fossil-fuels, efficiency.

\section{Introduction}

Sun is the most essential component of the universe as it distributes the sunlight towards the atmosphere. Sun distributes its sunlight uniformly and the intensity of sunlight varies from place to place. Although Sun intensity in the world is large enough calculated in MW'S and is sufficient to provide electricity at cheapest rates. Sun changes its position daily at constant intervals.

The time of intensity and requirement of our electricity is enough to get useful energy. Although the way to get solar energy in extensive amount differs lightly but one thing is common that the purpose is to get electrical energy after converting directly or indirectly. Except Antarctica and Arctic places, every part of the Earth is suitable place for solar energy [1].

The sun energy is the only energy which is free and available to everyone in the world. Today to produce electrical or mechanical energy, work or input is required which is usually not cheap and in general not free to people and fossils fuels are used to produce such energies. 
The use of fossils fuels are causing environment impure and also depletion of such resources is making decision makers upset. In many countries of the world where fossil fuels recourses are in great amount but they will be depleted in less than 100 years.

There are two solar technologies exiting today as they produce electricity directly or indirectly. First one is solar Panel technology and second one which is yet least common among people is solar thermal technology. Solar thermal technology is also called solar concentrated technology or solar concentrated power (CSP). The proposed model belongs to solar thermal technology, the second type of solar technology.

The proposed model parabolic solar dish produces electricity indirectly by concentrating sunlight towards the heat engine (commonly called Stirling Engine) [2]. The whole phenomena is that reflective material present on the front side of dish is used to reflect coming sunlight towards engine.

There are many choices of using reflecting mirrors. Although the mirror used should be good enough reflective to concentrate substantial amount of solar energy which Stirling engine requires to operate [3]. In front of the focal point of the dish, engine is mounted and on the engine, dynamo is coupled (DC) through a rubber belt.

Stirling engine is a heat engine and in the proposed system "Gamma" type Stirling engine is being used in which two cylinders are used and a displacer in hot cylinder and power piston in cold cylinder are used. When sunlight heats the hot cylinder after sometime, the engine starts operating and with the dynamo being coupled, produces electricity [4].

The electricity produced can be stored or can be used to run load or in parallel both purposes can be achieved. In other words in this proposed system two conversions occurs, firstly heat to mechanical and secondly mechanical to electrical energy contrary to solar panels in which heat is directly converted into electricity.

The solar panel technology is most famous but this technology is new. Solar thermal technology can provide two useful outputs [5], [6].

Firstly it can provide central heating system, hot water, steam and secondly it can also provide electricity to users. The use of parabolic solar dish for cooking is not new but this phenomenon is very old and Greeks, Romans civilizations used that principle for cooking and in today life, in offline areas, especially in desert places, the use of solar cooking is also common and old [7], [8].

To generate electricity using parabolic solar dish is quite innovate and interesting approach. Solar thermal systems have best efficiency in terms of maintenance, operation and in service life. There service life is usually 30-40 yrs larger than existing solar panels and other small generators. If they are used in plants in series for power required in MW or in KW they are still yet preferable [9].

\section{Proposed System}

\subsection{Methodology}

The whole mechanism of the system is simple. Light Dependent Resistor sensors are used to track sun and to keep the dish in front of sun. If sunlight is not available, solar tracker can't track dish and hence no electricity will be generated. On the other hand, if sunlight is available, solar tracker will start tracking the sun and sunlight is focused to the cylinder of the engine which is kept at the point of convergence of the dish. This Stirling engine is coupled to a Dynamo through a rubber belt and the dynamo produces output. In proposed system, window reflecting tape of polished aluminum considering cost, efficiency and reliability have been used.

\subsection{System Flow Chart}

See the system flow chart in blow Fig. 1: 


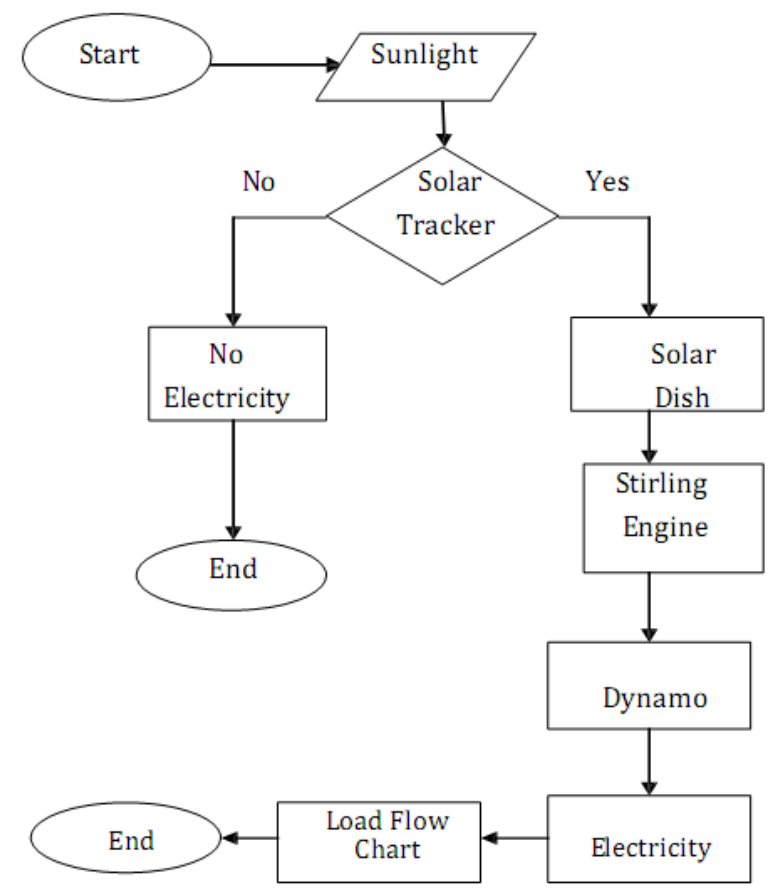

Fig. 1. Flow chart.

\section{Components Used in This System}

\subsection{Stirling Engine}

Gamma Stirling engine is a collaboration of alpha and beta Stirling engine. Gamma Stirling engine consist of a piston and a displacer that are located in separate cylinders rather than in one cylinder as in beta Stirling engine. In one cylinder the displacer undertakes its function and in other cylinder the piston controls the deviations of volume. In gamma Stirling engine the heat exchangers are connected with displacer cylinder and the expansion and compression work space is connected with piston. Gamma provides an appropriate parting between the heat exchangers and the expansion and compression work space. In Stirling engine the gas can flow freely between the two cylinders. Its structure is simple due to the presence of two cylinders and only piston needed to be sealed. Fig. 2 shows pistons of a gamma Stirling engine.

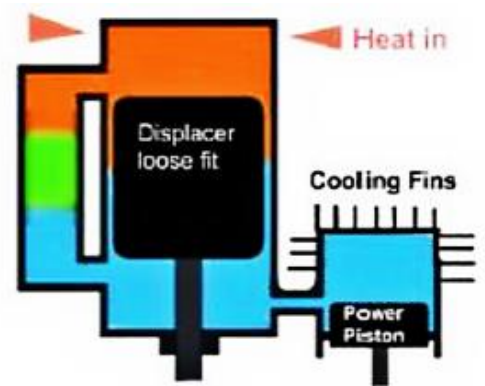

Fig. 2. Pistons of a gamma Stirling engine.

Why we used Stirling engine?

There are many reasons for using Stirling engine. Some of them are as

- Stirling engine is not hazardous to use because we do not need to produce steam at high pressure as in boiler.

- Stirling engine consist of a piston and a displacer located in a cylinder. Inside the cylinder there is 
no need of explosions for running the piston as in Otto or diesel engine.

- Stirling engine stop the noise production because there are no intake and exhaust valves. Valves are major cause of noise production.

- In Stirling engine the gas (air, helium or nitrogen) which is used as a working fluid do not need to be refill.

- In Stirling engine the external heat can be used from any heat source what you want i-e fuel, oil, gas, biomass, solar or geothermal heat.

- If we use the external heat from renewable energy sources like solar energy than there is no emission.

- Stirling engine can easily run even with a small temperature difference.

\subsection{Solar Parabolic Dish}

Solar parabolic dish is one of the type of concentrated solar technology used to focus the sunlight at a single fixed point called a focal point. This focal point varies from dish to dish due to different tolerances. It uses different reflecting materials like polished aluminum, silver, mirrors etc. to reflect the sunlight onto the cylinder. It uses dual axis sun tracker to track sunlight. The dish is seated on an architecture that trail the sun repeatedly all over the day to emulate the maximal percentage of sunlight possible onto the cylinder of the engine [8]. This heat energy is used to run the Stirling engine. A Stirling engines uses the heated fluid to displace pistons and produce mechanical power. The mechanical work, in the form of the rotation of the engine's crankshaft, turns a generator and yield electrical power. Solar parabolic dishes can reach temperature above $1000{ }^{\circ} \mathrm{C}$ [10], [11]. High optical efficiency and low startup losses make dish/engine systems the utmost powerful of all solar technologies. A solar dish is shown in Fig. 3.

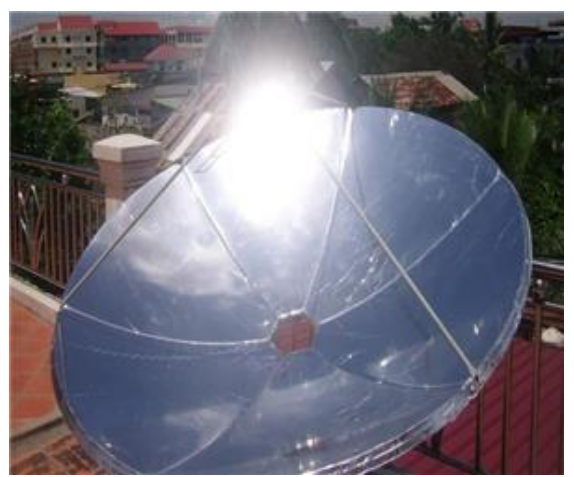

Fig. 3. Solar parabolic dish.

\subsubsection{Scientific and technical data}

Sun Surface temperature $=$ around 6000 to $10,000 \mathrm{~K}$ Radiation energy flux $=$ about $63 \mathrm{MW} / \mathrm{m}^{2}$

Energy flux $=1300 \mathrm{~W} / \mathrm{m}^{2}$ out of earth atmosphere.

Distance from the sun $=1.5^{*} 10^{11} \mathrm{~m}$

Sun diameter $=1.39 * 10^{9} \mathrm{~m}$

Sun surface heat flux $=4.6^{*} 10^{4}$ times than that out of the earth atmosphere.

\subsubsection{Factors considered during designing}

While designing a parabolic dish, the two main keys were kept in mind.

- One is that the shape of the dish should be as so that entering rays which are horizontal to the dish's axis will be emulated in the direction of the target.

- The second is that the light rays from the sun appears at the Earth's surface are totally horizontal. 
So all of the incoming radiations will be emulated in the direction of the focal point of the dish.

\subsubsection{Efficiency}

Efficiency of a solar dish depends on

- Concentrator design parameter.

- Operating conditions parameters i.e. solar flux, inlet temperature, ambient temperature.

- Concentration ratio C

- Intercept factor i.e. Fraction of incident beam radiation that is intercepted by the receiver at normal incidence.

- Angle of incidence i.e. angle between solar rays and surface normal.

\subsubsection{Physically measured parameters}

From engineering point of view, diameter, depth, focal point, area and intensity are the main parameters regarding solar parabolic dish. Each of these parameters must be taken under consideration while designing this type of system. These parameters require accuracy for better efficiency and much production. Some of these parameters measured physically in proposed model are given in Table 1.

Table 1. Parameters of Solar Parabolic Dish

\begin{tabular}{|c|c|}
\hline Parameters & Dimensions \\
\hline Diameter & $1.21 \mathrm{~m}$ \\
\hline Focal Point & $0.4618 \mathrm{~m}$ \\
\hline Depth & $0.2017 \mathrm{~m}$ \\
\hline Area of dish & 1.1674 meter square \\
\hline Parabolic & Yes \\
\hline Body & Aluminum \\
\hline Reflecting Material & PVC \\
\hline Reflection & $75 \%$ \\
\hline
\end{tabular}

\subsection{Electric Dynamo}

An electric generator change mechanical energy into electrical energy in the presence of electromagnetic induction. This is done by displacing a conductor through a magnetic field; when conductors are displaced with a magnet, it produces current in the conductor which is moving continually. The mechanical energy in the conductor is converted into electricity which in turn goes into wires. The shaft on ahead of a generator gives the mechanical energy to run the generator on by spinning the metal wires which are inner into the magnetic field. This is responsible to pass the current in the wires which are joined with volt meter. A volt meter shows the amount of electricity produced. Structure of dynamo electric machine in accordance with the invention is described in Fig. 4.

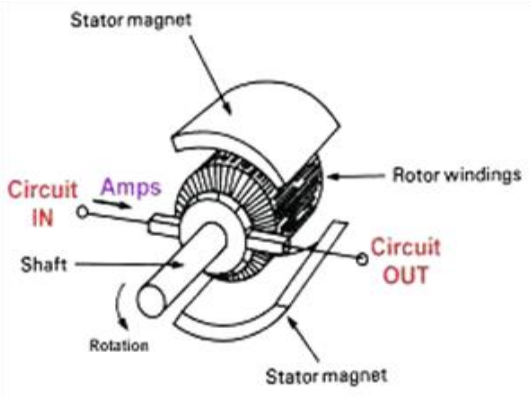

Fig. 4. Structure of electric dynamo. 


\section{Solar Tracking System}

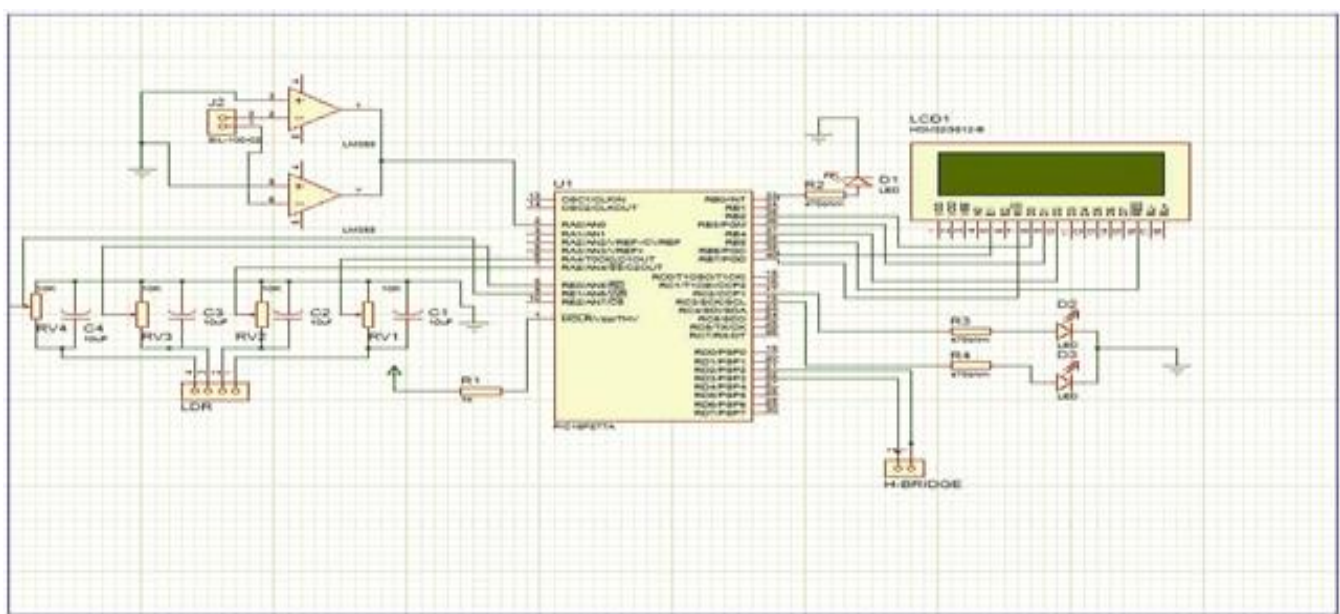

Fig. 5. Main tracker circuit.

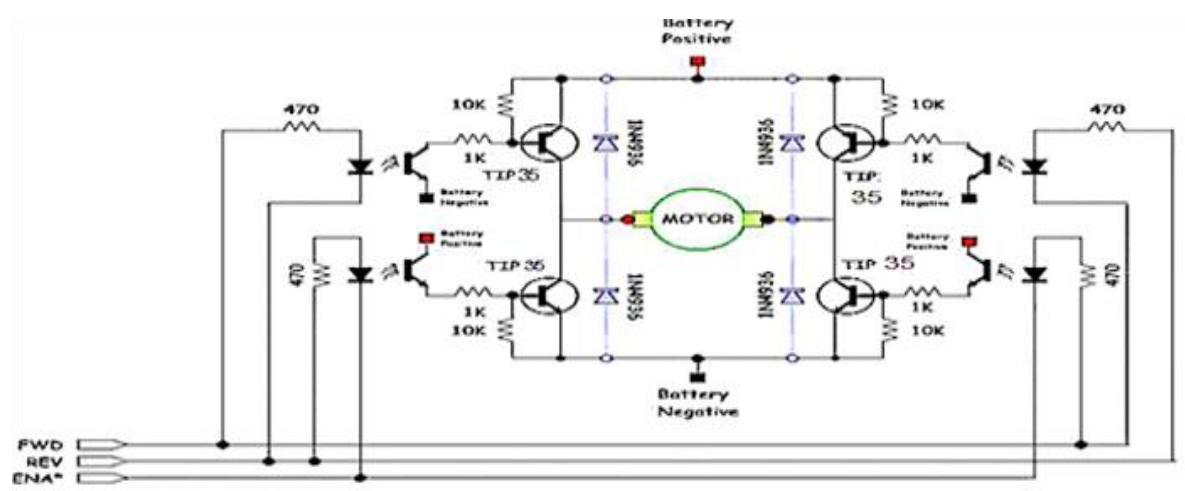

Fig. 6. H bridge circuit.

The solar tracking circuits are denoted in Fig. 5, Fig. 6, it uses LDR to sense sunlight and move in that direction to get maximum sunlight. The perpendicular and parallel motion of solar concentrator is attained by taking altitude angle and azimuth angle as reference. The microcontroller PIC 16F877A has been used to control the position of DC motors. The mathematical simulation control of dual axis solar tracking controls the point by point motion of the DC motors while tracking the sun. The system identify the maximal severity of light, when there is a fall in intensity of light, the system will naturally change it direction by a motor to attain a maximal severity of light. The physical designed circuit for solar tracker is denote in Fig. 7, Fig. 8, below.

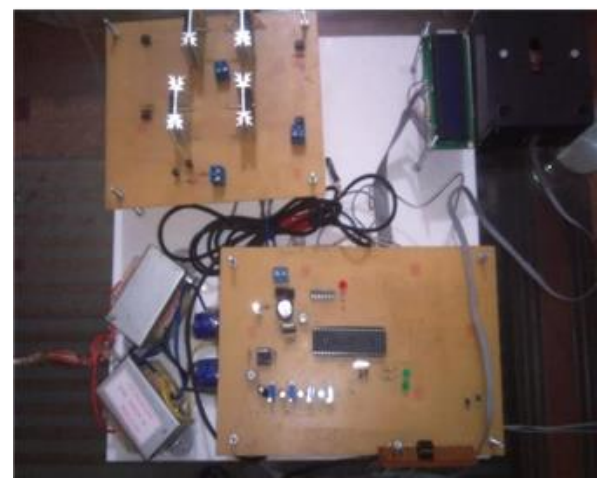

Fig. 7. Circuit for solar tracker. 


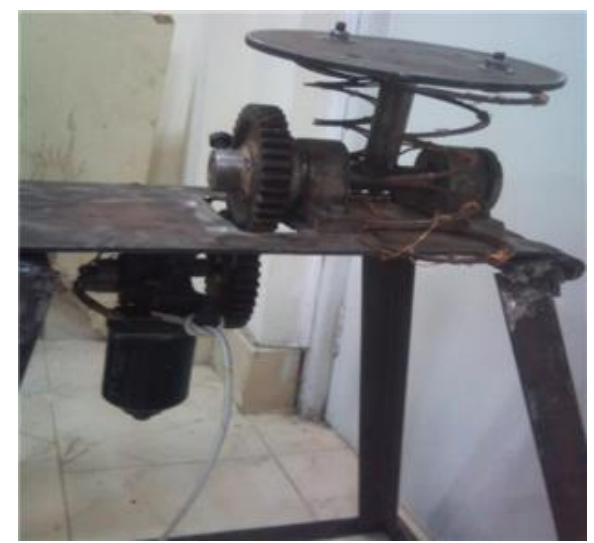

Fig. 8. Mechanical structure.

\section{Observations and Calculations}

Heat from a solar dish perhaps employed to run a heat engine turning in a cycle to yield the work. A heat engine perhaps used for alike utilization as water pumping and producing electricity.

The thermal output $Q_{\text {out }}$ of a contemplating material running at temperature $\mathrm{T}$ is given by

$Q_{\text {out }}=F^{\prime}\left[\right.$ gamma. $\left.A_{\text {in }} \mathrm{q}_{\text {in }}-U \cdot A_{\text {rec }}\left(T-T_{\mathrm{a}}\right)\right]$,

in $A$ : the area of the incident solar radiation $\left(\mathrm{m}^{2}\right)$.

${ }^{\operatorname{rec}} A$ : the area of the receiver $\left(\mathrm{m}^{2}\right)$ i-e cylinder of the engine. gamma: optical efficiency

${ }^{\text {in }} q$ : the incident solar irradiation $\left(\mathrm{W} / \mathrm{m}^{2}\right)$

$T_{\mathrm{a}}$ : the ambient temperature $\left({ }^{\circ} \mathrm{C}\right)$

$U$ :the heat loss coefficient $\left(\mathrm{W} / \mathrm{m}^{2} \mathrm{~K}\right)$

$F$ :collector efficiency factor

The quantity $A_{\text {in }} / A_{\text {rec }}$ is called the concentration ratio.

High intensity ratios are attained by forming $A_{\text {in }}$ the area of a dish designed to target the solar radiation accepted onto a mini receiver (engine) of area $A_{\text {rec. }}$. Heat losses from the receiver (engine) are decreased by the smaller size of the receiver. Thereon, high intensity ratios give high dish temperatures. The stagnation temperature Tmax is given by:

$$
\text { gamma } \cdot A_{\text {in }} q_{\text {in }}=\mathrm{U} \cdot A_{\text {rec }}\left(T_{\max }-T_{\mathrm{a}}\right)
$$

${ }^{2}$ For example, if the optical efficiency is gamma $=0.8$, the incident solar irradiation is $q_{\text {in }}=800 \mathrm{~W} / \mathrm{m}$, the ambient temperature is $T_{\mathrm{a}}=30^{\circ} \mathrm{C}$, and the heat loss coefficient is $U=10 \mathrm{~W} / \mathrm{m}^{2} \mathrm{~K}$, then a concentration ratio $A=1\left(\right.$ no $/ A$ ) (concentration) gives $T_{\max }=94^{\circ} \mathrm{C}$, and a intensity ratio

$$
A_{\text {in }} / A_{\text {rec }}=10 \text { gives } T_{\text {max }}=670^{\circ} \mathrm{C}
$$

The dish efficiency $e t a_{\mathrm{C}}$ at operating temperature $T$ is

$$
\begin{gathered}
e t a_{\mathrm{C}}=Q_{\text {out }} / A_{\text {in }} q_{\text {in }}=F\left[\text { gamma }-\mathrm{U} \cdot A_{\text {rec }}\left(T-T_{\mathrm{a}}\right) / A_{\text {in }} q_{\text {in }}\right] \\
=F^{\prime} g a m m a\left(T_{\text {max }}-T\right) /\left(T_{\text {max }}-T_{\mathrm{a}}\right) .
\end{gathered}
$$

The attainable mechanical power from the thermal power outcome of the dish that is wishful to attained by employing a Carnot cycle is $Q_{\text {out }}\left(1-T_{\mathrm{a}} / T\right)$, where the temperatures are absolute temperatures.

The second law efficiency eta 2 of a heat engine is defined by

$$
\text { eta } 2=(\text { mechanical power delivered })
$$




\section{/(available mechanical power).}

Suppose a heat engine with second law efficiency eta2 employs as input the thermal power $Q_{\text {out }}$ from the solar dish. The $1^{\text {st }}$ law efficiency of the engine is

$$
\text { eta } 1=(\text { mechanical power delivered }) / Q_{\text {out }}=e t a 2\left(1-T_{\mathrm{a}} / T\right),
$$

where $T_{\max }$ lies on the pattern of the dish and on the solar radiation input $q_{\mathrm{in}}$. Now, given $\mathrm{F}^{\prime}$, gamma, eta2, $T_{a}$, and $T_{\text {max }}$ it can be acquisit the maximum efficiency attainable, and the optimal running temperature $T_{\mathrm{opt}}$ from the condition $d($ eta $) / \mathrm{d} T=0$. This appears at the optimal temperature [12], [13].

$$
T_{\text {opt }}=\left[T_{\max } T_{\mathrm{a}}\right],
$$

And the maximal efficiency is attained by inserting:

$$
T=T_{\text {opt }}
$$

For example, putting $\mathrm{F}^{\prime}=0.9$, gamma $=0.8$, eta $2=0.6, \mathrm{~T}_{\mathrm{a}}=30^{\circ} \mathrm{C}=303 \mathrm{~K}$, we obtain the efficiencies etamax for different degrees of concentration denote in Table 2. Very low total efficiencies are attained except running temperatures higher than $500^{\circ} \mathrm{C}$ are used. Pricey concentrating systems are required to attain these high temperatures, so commercial growth is crucial.

Table 2. Different Degrees of Concentration

\begin{tabular}{|c|c|c|}
\hline $\mathbf{T}_{\mathbf{m a x}}$ & $\mathbf{T}_{\mathbf{O p t}}$ & etamax \\
\hline $100^{\circ} \mathrm{C}$ & $63^{\circ} \mathrm{C}$ & $2.2 \%$ \\
\hline $200^{\circ} \mathrm{C}$ & $106^{\circ} \mathrm{C}$ & $4.8 \%$ \\
\hline $400^{\circ} \mathrm{C}$ & $179^{\circ} \mathrm{C}$ & $8.5 \%$ \\
\hline $800^{\circ} \mathrm{C}$ & $297^{\circ} \mathrm{C}$ & $13.2 \%$ \\
\hline $1600^{\circ} \mathrm{C}$ & $480^{\circ} \mathrm{C}$ & $18.4 \%$ \\
\hline
\end{tabular}

\section{Conclusion}

First conclusion about system is that it can be installed in offline areas like deserts and in urban life. The requirement of power can be varied at different places according to the need but system has higher portability capabilities.

Second conclusion is that project efficiency as calculated is higher than existing solar thermal types and solar panels. This is due to the fact that solar dish focuses sunlight at a point where maximum sunlight falls.

Third conclusion about the system is that minor changes in the intensity of sunlight usually do not suffer engine performance and use of Stirling engine is dish Stirling is one of the best technique to be used here. In short it is due to also Stirling engine that parabolic dish system has higher efficiencies due to the fact that it gives higher efficiencies from heat to mechanical.

In the last parabolic solar dish using Stirling engine is one of the best techniques to produce electrical energy at higher efficiencies. It can play a very significant and positive role in reducing the higher utility bills and reducing shortage of electricity.

\section{References}

[1] Lund, K. O. A. (1996, Feb.). Direct-heating energy-storage receiver for dish Stirling solar energy systems. J. Sol Energy Eng., 118(1), 15.

[2] Stine, W. B. (1989). Progress in Parabolic Dish Technology. Golden, CO: National Renewable Energy Laboratory. 
[3] Smith, T. (2007). Concentrating Solar Power Technology Workshops. Infinia Corporation Presentation.

[4] Sagade, A., \& Shinde, N. (2012). Performance evaluation of parabolic dish type solar collector for industrial heating application. International Journal of Energy Technology and Policy, 8 (1), pp.80-93.

[5] Eswaramoorthy, M., \& Shanmugam. (2010). Thermodynamic analysis of solar parabolic dish thermoelectric generator. International Journal of Renewable Energy Technology, 1 (3), 348-360.

[6] Jorgenson, G. (1993). Reflective coatings for solar applications. Proceedings of the 36th Annual Technical Conference Proceedings of the Society of Vacuum Coaters (pp. 23-31).

[7] Cooke, D. (2011, April). Single vs. dual axis solar tracking. Alternate Energy eMagazine.

[8] Mancini, T. R. (1997). Solar-electric dish Stirling system development. Sandia National Laboratories, USA, SAND- 97-2924C.

[9] Luque-Heredia, I., et al. (2012). The Sun Tracker in Concentrator Photovoltaics. Next Generation Photovoltaics, Springer Verlag.

[10] Engines, S., \& Walker, G. (1980). Stirling Cryocoolers. Oxford: Clarenden Press.

[11] Dickinson, W. C., \& Cheremisinoff, P. N. (1980). Solar Energy Technology Handbook. New York: Marcel Dekker Co.

[12] Droher, J. J., \& Squier, S. E. (1986). Performance of the Vanguard Solar Dish-Stirling Engine Module. EPRI APCPG 4608. Palo Alto, CA: Electrical Power Research Institute.

[13] Concentrating Collectors. Retrieved from https://www.scribd.com/presentation/54393284/Concentrating-Collector-Serkan-Kapucu
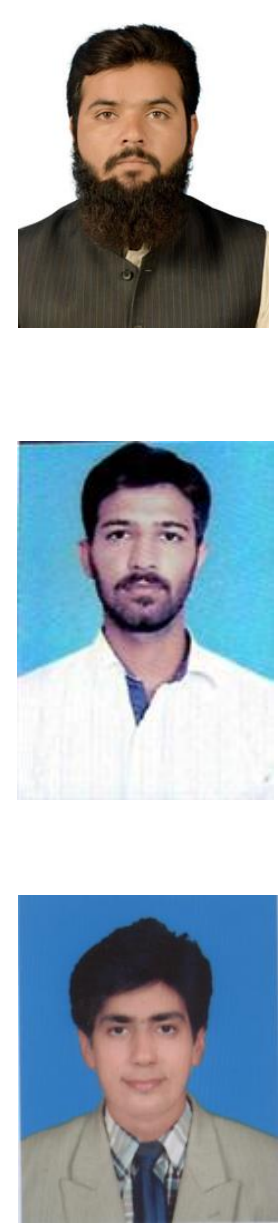

Abubakar Siddique received the BSc \& MSc degrees in electrical engineering from the Islamia University Bahawalpur, Pakistan, in 2011 and 2009 respectively. He is pursuing the $\mathrm{PhD}$ degree from School of Electrical \& Electronics Engineering, North China Electric Power University, 102206, Beijing, China. His research area is FACTS (UPFC), power quality, renewable energy and voltage stability.

M. Waqar Hassan received the BSc in electrical engineering from the Islamia University Bahawalpur, Pakistan in 2017. His research area is renewable energy, power quality and voltage stability.

M. Kaleem Aslam received the BSc in electrical engineering from the Bahaudin Zikriya University Multan, Pakistan and the MSc degrees in electrical engineering from Institute of Southern Punjab (ISP) Multan, Pakistan, in 2015 and 2018 respectively. His research area is power quality, ANN, renewable energy and voltage stability. 


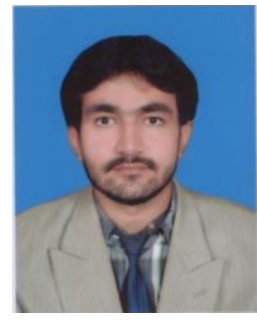

M. Nadeem Aslam received the BSc in electrical engineering from the Bahaudin Zikriya University Multan, Pakistan and the MSc degrees in electrical engineering from Institute of Southern Punjab (ISP) Multan, Pakistan, in 2015 and 2018 respectively. His research area is power quality, ANN, renewable energy and voltage stability.

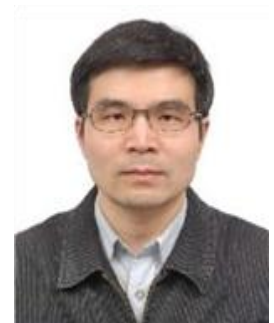

Yonghai Xu was born in April 1966. In 1989, he got the bachelor's degree of engineering from Tsinghua University. In 1992, he got the degree of master of engineering from North China Electric Power Institute. In 2002, he got the degree of doctor of engineering from Harbin Institute of Technology. His current major directions of research include: (1) analysis and control of power quality; (2) new energy electric systems.

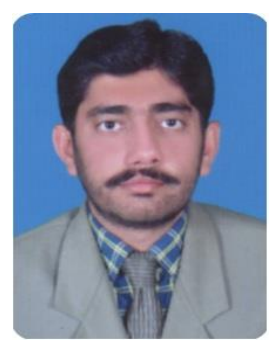

Waseem Aslam received the BSc \& MSc degrees in electrical engineering from the Islamia University Bahawalpur, Pakistan, in 2011 and 2009 respectively. He is pursuing $\mathrm{PhD}$ degree from School of Electrical \& Electronics Engineering, North China Electric Power University, 102206, Beijing, China. His research area is FACTS, power quality, renewable energy and voltage stability. 